\title{
Bias in the Evaluation of Conflict of Interest Policies
}

\author{
Zachariah Sharek, Robert E. Schoen, and George Loewenstein
}

\section{Introduction}

A wide range of medical institutions have developed and implemented policies to mitigate the adverse consequences of conflicts of interest. These newly implemented policies, which include regulation of industry contact with physicians and hospitals, controls on gifts from industry, and greater transparency in industry sponsored activities, have generated considerable controversy. ${ }^{1}$

Formulating and evaluating policies in a neutral, unbiased fashion can be difficult for those personally affected. When people have a stake in an issue, they tend to process information in a selective fashion that supports their personal interests, a phenomenon known as "motivated reasoning." ${ }^{2}$ When decision makers with preexisting opinions are exposed to information, they are inclined to selectively use the information to arrive at conclusions that justify their prior beliefs. ${ }^{3}$ When confronted with information that contradicts existing views, people evaluate it with greater skepticism. ${ }^{4}$ Additionally, once decision makers have reached a decision, they are likely to evaluate subsequent evidence in a biased manner that supports their decision. ${ }^{5}$ Moreover, while most people are ready to accept the possibility of bias in others, few are ready to acknowledge that they themselves might be biased - a phenomenon Pronin and coauthors dub the "bias bias." 6 Physicians are not exempt from "bias bias"; several studies have found that physicians, on average,

Zachariah Sharek is a Ph.D. candidate at the Tepper School of Business, Carnegie Mellon University. Robert Schoen, M.D., MPH, is a professor of Medicine and Epidemiology at the University of Pittsburgh. George Loewenstein, Ph.D., is the Herbert A. Simon Professor of Economics and Psychology in the department of Social and Decision Sciences at Carnegie Mellon University. accept that other physicians might be biased by conflicts of interest, but few are ready to recognize that they too might be just as vulnerable to bias. ${ }^{7}$

One way to evaluate the impact of bias in a policy domain such as conflict of interest is to have comparable groups of people evaluate policies that are expressed in a form either related to, or seemingly unrelated to, their personal situation. With this goal, we requested feedback from physicians, financial planners, and control subjects on a conflict of interest policy that was presented in two different contexts, one related to medicine and the other to financial services. Our goal was to see whether physicians would evaluate the same conflict of interest policy differently when it was presented in a medical as opposed to a financial context. We hypothesized, as suggested by research on motivated bias, that physicians would have a less favorable perception of the conflict of interest policy, and a more favorable perception of the objections raised against it, when it was presented in a medical as opposed to a financial context.

\section{Methods}

\section{Study Population}

Participants, who completed a web-based survey in the winter of 2008, were recruited from three sources. (1) Physicians participating in clinical care at the University of Pittsburgh Medical Center were asked by email to participate in a survey about conflict of interest policy. As an incentive, an iPod was awarded to every 100th participant. A URL address that could be clicked on to access the survey was provided in the email. (2) Financial planners were recruited via an email sent out to subscribers to Research Magazine, an Oakland, California publication that describes itself as "the publication that helps financial advi- 
sors help their clients.") Lastly, a separate sample was recruited via a link in the online version of the Nerw York Times (NYT) in a weekly science section called "Tierney Blog," which reports on a variety of scientific issues. For inclusion, a respondent had to complete all questions (except demographics). To increase the comparability of age distributions across samples, respondents who were $<25$ years old were excluded from all samples.

\section{Experimental Materials}

On entering the website, participants from each of the three samples were randomly assigned to evaluate a conflict of interest policy cast in either a medical or financial services sphere. In the medical sphere, the conflict of interest that the policy dealt with involved relationships between physicians and the pharmaceutical industry. In the financial sphere, it dealt with relationships between personal financial planners and companies that market investments. ${ }^{8}$ The policies in the two domains were written in parallel, with only those minimal wording differences necessary to refer to financial planners versus doctors and financial companies versus pharmaceutical companies. The medical and financial conflict of interest policies are presented in Appendix A.

After reading the proposed policies, participants in the medical policy condition responded to four statements, presented in random order, using a five-point scale with response options: strongly disagree, disagree, neither agree nor disagree, agree, and strongly agree:

- I believe the proposed policies are reasonable.

- These policies will help Hospital X to avoid potential conflicts of interest.

- Doctors are licensed professionals. We should be able to rely on them to avoid conflicts of interest without these onerous regulations.

- Knowing that Hospital X had implemented these guidelines would encourage me to seek medical advice from them.

Next, participants were presented with six objections to the conflict of interest policy, which were distillations of letters written by actual doctors protesting the introduction of a COI policy similar to the one used in our experiment. These six objections, presented in random order, centered on: (1) a lack of evidence that a problem exists; (2) a lack of evidence that the policies would help; (3) the lack of need for intervention given professional norms of behavior; (4) the view that disclosure of the conflicts constituted a sufficient intervention; (5) the opinion that the policy is selectively biased against doctors and/or against specific
COIs that doctors face; and (6) purported conflicts on the part of those proposing the policy. For example, the objection based on the lack of evidence of a problem was presented as:

The revised policies are based on conjecture rather than actual evidence. While it would be naïve to maintain that relationships with pharmaceutical companies do not introduce potential conflicts of interest, there is no evidence that free pens or coffee mugs affect medical decisions.

All six objections were applied similarly to the financial management context.

After each objection, participants were asked: "In your opinion, is this a reasonable argument against the new conflict of interest policy... " with a three-part possible response: "Not at all reasonable," "somewhat reasonable," and "very reasonable."

Finally, after responding to the six objections, participants were asked to evaluate how these objections changed their opinions regarding the four policy questions they had originally answered at the beginning of the survey. They were shown the four policy questions and asked to respond "relative to your response at the beginning of the survey" using a scale with options from 1: "Disagree with the statement much more strongly" to 5: "Agree with the statement much more strongly."

\section{Statistical Analyses}

Responses were analyzed using analysis of variance (ANOVA). In addition, omnibus analyses using multivariate analysis of variance (MANOVA) tested for an overall effect involving all of the subsidiary items. In both of these types of analyses, responses to the questions served as the dependent variables and the domain to which the policy applied (medicine or financial advice), and profession of the respondent (physician or non-physician) were the independent variables.

For each of these analyses, we hypothesized that physicians evaluating the medical scenario would be outliers, in the direction of being less favorable toward the policy and more accepting of the objections to the policy. Similarly, we hypothesized that the financial planners evaluating the financial scenario would also be outliers, viewing the financial conflict of interest policy less favorably and more accepting of the objections to the policy. The key statistical test of this predicted pattern of results is the statistical interaction effect between the domain to which the policy applied and the profession of the respondent. A significant interaction effect indicates that respondents reacted differently to the two types of policies in a fashion that depended on their own profession. 


\section{Results}

One hundred and seventy nine responses were obtained from physicians at the University of Pittsburgh Medical Center (UPMC), from an email list of 1527 doctors for a response rate of $11.7 \%$. Two hundred and twenty-four financial planners responded to an "email blast" from Research Magazine. Thirteen hundred and six responses were obtained from visitors to the New York Times (NYT) website In total, 946 participants responded to the questions in the medical scenario (89 doctors, 111 financial planners, and 746 NYT respondents) and 763 answered the questions in the financial scenario (90 doctors, 113 financial planners, and 560 NYT respondents).

Table 1 presents the characteristics of the participants. UPMC physicians tended to be more concentrated in the middle age categories than NYT respondents, whereas the financial planners were older on average, but were not different by race. Both the financial planners and doctors were mainly male, while the NYT respondents were more evenly split. Table 1 also presents the breakdown of self-reported professions of the NYT sample. The highest fraction of respondents is unclassified - in "other" - but among those classified, the largest fraction $(24.0 \%)$ are in "education or social services."

\section{Initial Reactions to the Policy}

Figure 1 shows the mean initial response to summary statements about the COI policy for UPMC physicians vs. the financial planners vs. the NYT sample, and by medical vs. financial services scenario. Responses to all four questions show a pattern consistent with motivated bias. Those in the NYT sample demonstrate a similar attitude toward the conflict of interest policy, whether in the medical or financial services context. UPMC Physicians were similar to the NYT sample in

Table I

Demographic Characteristics of the Physician, Financial Planner and New York Times Samples

\begin{tabular}{|c|c|c|c|c|}
\hline & & $\begin{array}{l}\text { UPMC Doctors (n } \\
=179)\end{array}$ & $\begin{array}{c}\text { New York Times (n } \\
=1306)\end{array}$ & $\begin{array}{c}\text { Financial Planners } \\
(n=224)\end{array}$ \\
\hline \multirow{6}{*}{ Age \% (n) } & 25 to 34 & $4.5(8)$ & $20.2(264)$ & $7.6(17)$ \\
\hline & 35 to 44 & $32.4(58)$ & $20.8(271)$ & $17.0(38)$ \\
\hline & 45 to 54 & $37.4(67)$ & $25.7(336)$ & $32.1(72)$ \\
\hline & 55 to 64 & $19.6(35)$ & $24.2(316)$ & $27.2(61)$ \\
\hline & Over 64 & $6.1(11)$ & $8.6(112)$ & $16.1(36)$ \\
\hline & No Response & $0.0(0)$ & $0.5(7)$ & $0.0(0)$ \\
\hline \multirow{3}{*}{ Gender \% (n) } & Male & $70.4(126)$ & $53.1(694)$ & $84.4(189)$ \\
\hline & Female & $26.8(48)$ & $44.0(575)$ & $15.6(35)$ \\
\hline & No Response & $2.8(5)$ & $2.8(37)$ & $0.0(0)$ \\
\hline \multirow{6}{*}{ Race \% (n) } & White & $84.9(152)$ & $86.7(1132)$ & $92.9(208)$ \\
\hline & Black & $0.0(0)$ & $1.2(16)$ & $0.4(1)$ \\
\hline & Hispanic & $1.7(3)$ & $1.9(25)$ & $1.3(3)$ \\
\hline & Asian & $8.9(16)$ & $4.2(55)$ & $3.6(8)$ \\
\hline & Other & $3.4(6)$ & $4.2(55)$ & $1.8(4)$ \\
\hline & No Response & $1.1(2)$ & $1.8(23)$ & $0.0(0)$ \\
\hline \multirow{8}{*}{ Industry \% (n) } & Finance & $0.0(0)$ & $5.1(67)$ & $100.0(224)$ \\
\hline & Medicine & $100.0(179)$ & $10.1(132)^{1}$ & $0.0(0)$ \\
\hline & Manufacturing & $0.0(0)$ & $4.1(54)$ & $0.0(0)$ \\
\hline & $\begin{array}{r}\text { Education and Social } \\
\text { Services }\end{array}$ & $0.0(0)$ & $25.8(337)$ & $0.0(0)$ \\
\hline & $\begin{array}{r}\text { Arts, Entertainment } \\
\text { and Food } \\
\end{array}$ & $0.0(0)$ & $4.7(62)$ & $0.0(0)$ \\
\hline & Public Administration & $0.0(0)$ & $4.7(62)$ & $0.0(0)$ \\
\hline & Other & $0.0(0)$ & $43.8(572)$ & $0.0(0)$ \\
\hline & No Response & $0.0(0)$ & $1.5(20)$ & $0.0(0)$ \\
\hline
\end{tabular}

${ }^{1} 132$ respondents listed medicine as their industry, of these, 98 were doctors 
Figure I

Mean responses with $\mathbf{9 5 \%}$ confidence intervals (bars) to the four policy questions. Participants answered on a scale from "Strongly Disagree (I)" to "Neither agree nor disagree/Neutral (3)" to "Strongly Agree (5)".

Policy 1- Reasonable

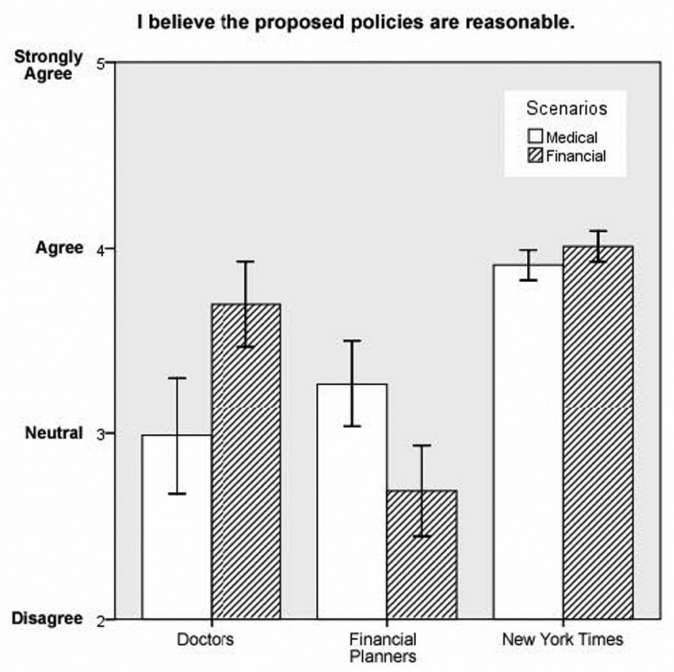

Policy 3- Professionals Don't need policy

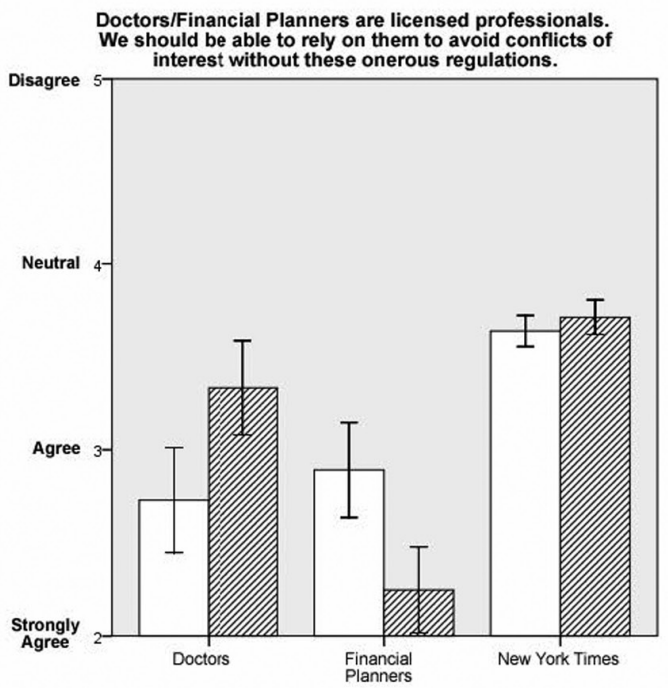

their assessment of the policy when it was cast in a financial context, but were less favorable toward the policy in a medical context. Financial planners also showed an asymmetry, but in the opposite direction; they viewed policy much less favorably when it applied to financial conflicts of interest than when it applied to medical conflicts of interest.

The first four rows of Table 2 present, in the 6 lefthand columns, a comparison of mean responses to the policy evaluation questions, breaking responses down by profession (physicians, financial planners, and NYT respondents) and scenario (medical and financial). The three right-hand columns present the significance
Policy 2- Will help avoid COI's
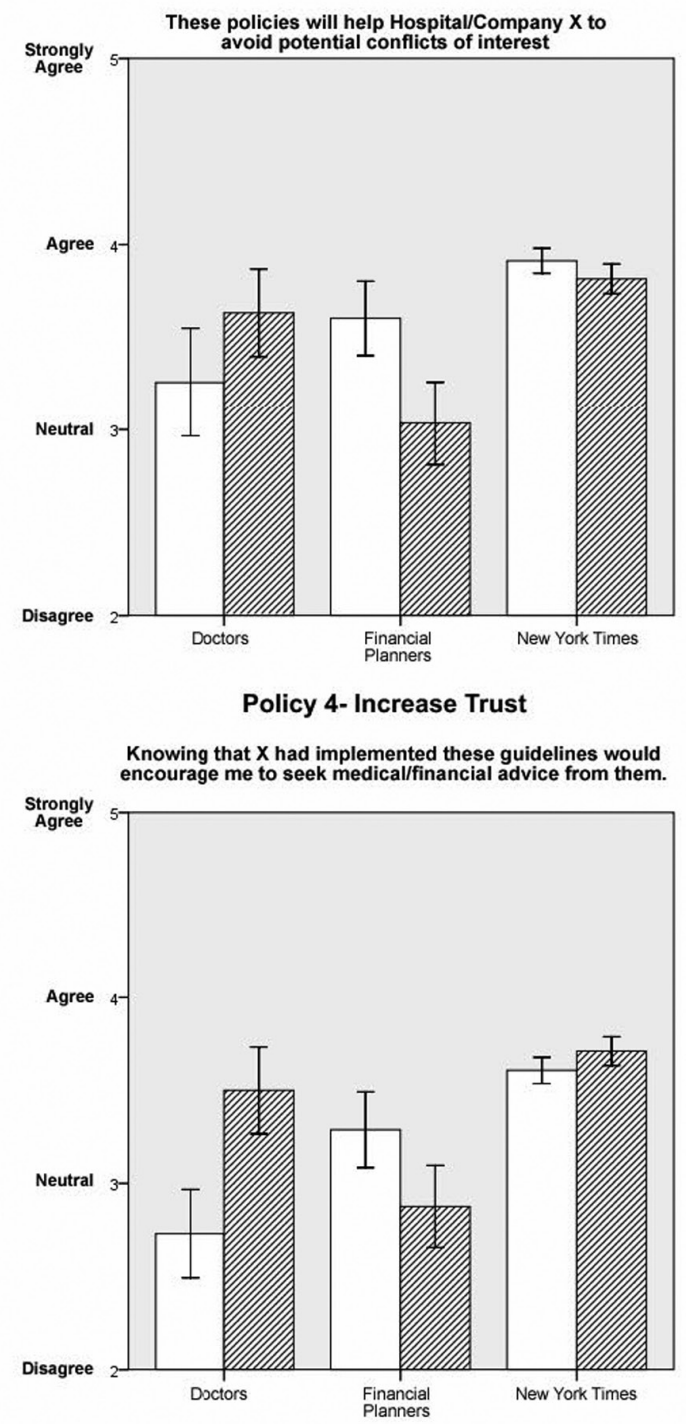

of the interaction terms from ANOVAs examining the impact of a sample (in each case comparing two of the three samples) and a scenario on the respondents' endorsement of the conflict of interest policy. The interaction effect in this ANOVA indicates whether respondents from the two samples being compared have a different relative reaction to the policies when they apply to the two domains (medical and financial). Thus, for example, the top left cell (at the intersection of the row labeled "Policy 1 " and the column marked "Physicians vs. NYT") indicates that the physicians and respondents from the NYT sample had a statistically significant different relative reaction to the first policy 
Table 2

Mean Values of COI Policy Questions, Responses to Objections and Adjusted Attitudes to the COI Policy by Profession and Scenario

\begin{tabular}{|c|c|c|c|c|c|c|c|c|c|}
\hline \multirow[b]{2}{*}{ Questions } & \multicolumn{6}{|c|}{ Means (SD) by Profession and Scenario } & \multicolumn{3}{|c|}{ Significance of Interaction } \\
\hline & $\begin{array}{r}\text { Phy } \\
\text { Medica } \\
1 \\
(\mathrm{n}=89) \\
\end{array}$ & $\begin{array}{l}\text { icians } \\
\text { Financi } \\
\text { al } \\
(n=90)\end{array}$ & 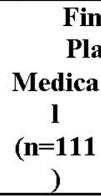 & $\begin{array}{l}\text { ncial } \\
\text { mers } \\
\begin{array}{c}\text { Financi } \\
\text { al } \\
(\mathrm{n}=113)\end{array} \\
\end{array}$ & $\begin{array}{c}\text { New Yo } \\
\text { Medica } \\
1 \\
(n=746 \\
)\end{array}$ & $\begin{array}{c}\text { rk Times } \\
\text { Financi } \\
\text { al } \\
(n=560)\end{array}$ & $\begin{array}{c}\text { Physicia } \\
\text { ns vs } \\
\text { NYT } \\
\end{array}$ & $\begin{array}{c}\text { Financia } \\
1 \\
\text { Planners } \\
\text { vs NYT }\end{array}$ & $\begin{array}{l}\text { Physicians } \\
\text { vs. Financial } \\
\text { Planners }\end{array}$ \\
\hline Policy 1 & $\begin{array}{c}2.99 \\
(1.49)\end{array}$ & $\begin{array}{l}3.7 \\
(1.1) \\
\end{array}$ & $\begin{array}{c}3.27 \\
(1.24)\end{array}$ & $\begin{array}{c}2.69 \\
(1.31)\end{array}$ & $\begin{array}{l}3.91 \\
(1.13)\end{array}$ & $\begin{array}{c}4.01 \\
(0.99) \\
\end{array}$ & $\mathrm{p}<.001$ & $\mathrm{p}<.001$ & $\mathrm{p}<.001$ \\
\hline Policy 2 & $\begin{array}{c}3.26 \\
(1.39)\end{array}$ & $\begin{array}{c}3.63 \\
(1.13)\end{array}$ & $\begin{array}{c}3.6 \\
(1.06)\end{array}$ & $\begin{array}{l}3.04 \\
(1.2) \\
\end{array}$ & $\begin{array}{l}3.91 \\
(0.93)\end{array}$ & $\begin{array}{c}3.82 \\
(0.96)\end{array}$ & $\mathrm{p}<.005$ & $\mathrm{p}<.001$ & $\mathrm{p}<.001$ \\
\hline Policy 3 & $\begin{array}{l}2.73 \\
(1.34)\end{array}$ & $\begin{array}{l}3.33 \\
(1.21)\end{array}$ & $\begin{array}{l}2.89 \\
(1.36)\end{array}$ & $\begin{array}{l}2.25 \\
(1.24)\end{array}$ & $\begin{array}{l}3.64 \\
(1.16)\end{array}$ & $\begin{array}{l}3.71 \\
(1.12)\end{array}$ & $\mathrm{p}<.005$ & $p<.001$ & $p<.001$ \\
\hline Policy 4 & $\begin{array}{c}2.73 \\
(1.13) \\
\end{array}$ & $\begin{array}{c}3.5 \\
(1.11)\end{array}$ & $\begin{array}{l}3.29 \\
(1.08) \\
\end{array}$ & $\begin{array}{l}2.88 \\
(1.18)\end{array}$ & $\begin{array}{c}3.61 \\
(0.99)\end{array}$ & $\begin{array}{c}3.71 \\
(0.93)\end{array}$ & $\mathrm{p}<.001$ & $\mathrm{p}<.001$ & $\mathrm{p}<.001$ \\
\hline $\begin{array}{c}\text { Policy } \\
\text { Average }\end{array}$ & $\begin{array}{c}2.92 \\
(1.15)\end{array}$ & $\begin{array}{c}3.54 \\
(0.95) \\
\end{array}$ & $\begin{array}{c}3.26 \\
(1.00)\end{array}$ & $\begin{array}{c}2.71 \\
(1.01)\end{array}$ & $\begin{array}{c}3.77 \\
(0.84)\end{array}$ & $\begin{array}{c}3.62 \\
(0.91)\end{array}$ & $\mathrm{p}<.001$ & $\mathrm{p}<.001$ & $p<.001$ \\
\hline Objection 1 & $\begin{array}{c}1.52 \\
(0.68) \\
\end{array}$ & $\begin{array}{c}1.29 \\
(0.52) \\
\end{array}$ & $\begin{array}{c}1.55 \\
(0.68) \\
\end{array}$ & $\begin{array}{c}1.67 \\
(0.76) \\
\end{array}$ & $\begin{array}{l}1.18 \\
(0.45) \\
\end{array}$ & $\begin{array}{c}1.19 \\
(0.44) \\
\end{array}$ & $\mathrm{p}<.005$ & NS & $p<.05$ \\
\hline Objection 2 & $\begin{array}{c}2.08 \\
(0.83)\end{array}$ & $\begin{array}{c}1.83 \\
(0.82)\end{array}$ & $\begin{array}{c}2.28 \\
(0.78)\end{array}$ & $\begin{array}{l}2.51 \\
(0.67)\end{array}$ & $\begin{array}{l}1.84 \\
(0.76)\end{array}$ & $\begin{array}{c}1.81 \\
(0.73)\end{array}$ & NS & $\mathrm{p}<.05$ & $\mathrm{p}<.005$ \\
\hline Objection 3 & $\begin{array}{c}1.89 \\
(0.75)\end{array}$ & $\begin{array}{c}1.87 \\
(0.84)\end{array}$ & $\begin{array}{c}1.92 \\
(0.74)\end{array}$ & $\begin{array}{l}2.22 \\
(0.78)\end{array}$ & $\begin{array}{c}1.63 \\
(0.68)\end{array}$ & $\begin{array}{c}1.62 \\
(0.77)\end{array}$ & NS & $p<.05$ & $p<.05$ \\
\hline Objection 4 & $\begin{array}{c}2.12 \\
(0.75)\end{array}$ & $\begin{array}{l}1.61 \\
(0.76)\end{array}$ & $\begin{array}{c}2.09 \\
(0.76) \\
\end{array}$ & $\begin{array}{l}2.43 \\
(0.75)\end{array}$ & $\begin{array}{l}1.58 \\
(0.7) \\
\end{array}$ & $\begin{array}{c}1.45 \\
(0.65)\end{array}$ & $\mathrm{p}<.001$ & $\mathrm{p}<.05$ & $p<.001$ \\
\hline Objection 5 & $\begin{array}{c}2.26 \\
(0.85) \\
\end{array}$ & $\begin{array}{l}1.79 \\
(0.74) \\
\end{array}$ & $\begin{array}{c}2.13 \\
(0.78) \\
\end{array}$ & $\begin{array}{c}2.1 \\
(0.71) \\
\end{array}$ & $\begin{array}{c}1.65 \\
(0.74) \\
\end{array}$ & $\begin{array}{c}1.54 \\
(0.64) \\
\end{array}$ & $\mathrm{p}<.005$ & NS & $\mathrm{p}<.005$ \\
\hline Objection 6 & $\begin{array}{c}1.87 \\
(0.77) \\
\end{array}$ & $\begin{array}{l}1.76 \\
(0.8) \\
\end{array}$ & $\begin{array}{c}2.14 \\
(0.77) \\
\end{array}$ & $\begin{array}{l}2.33 \\
(0.7) \\
\end{array}$ & $\begin{array}{c}1.56 \\
(0.69) \\
\end{array}$ & $\begin{array}{c}1.61 \\
(0.65)\end{array}$ & NS & NS & $\mathrm{p}<.05$ \\
\hline $\begin{array}{c}\text { Objection } \\
\text { Average }\end{array}$ & $\begin{array}{c}1.96 \\
(0.57) \\
\end{array}$ & $\begin{array}{c}1.69 \\
(0.57) \\
\end{array}$ & $\begin{array}{c}2.02 \\
(0.52) \\
\end{array}$ & $\begin{array}{c}2.21 \\
(0.52)\end{array}$ & $\begin{array}{c}1.57 \\
(0.44) \\
\end{array}$ & $\begin{array}{c}1.54 \\
(0.42)\end{array}$ & $\mathrm{p}<.005$ & $\mathrm{p}<.001$ & $\mathrm{p}<.001$ \\
\hline $\begin{array}{l}\text { Revised } \\
\text { Policy } 1 \\
\end{array}$ & $\begin{array}{l}2.71 \\
(0.8) \\
\end{array}$ & $\begin{array}{l}2.88 \\
(0.6) \\
\end{array}$ & $\begin{array}{c}2.86 \\
(0.96) \\
\end{array}$ & $\begin{array}{l}2.46 \\
(1.06)\end{array}$ & $\begin{array}{l}3.05 \\
(0.65) \\
\end{array}$ & $\begin{array}{c}3.11 \\
(0.59) \\
\end{array}$ & NS & $\mathbf{p}<.001$ & $\mathrm{p}<.001$ \\
\hline $\begin{array}{l}\text { Revised } \\
\text { Policy } 2 \\
\end{array}$ & $\begin{array}{l}2.79 \\
(0.7)\end{array}$ & $\begin{array}{c}2.96 \\
(0.63)\end{array}$ & $\begin{array}{c}3.09 \\
(0.84)\end{array}$ & $\begin{array}{l}2.67 \\
(1.03)\end{array}$ & $\begin{array}{l}3.05 \\
(0.63) \\
\end{array}$ & $\begin{array}{c}3.1 \\
(0.63)\end{array}$ & NS & $\mathrm{p}<.001$ & $\mathrm{p}<.001$ \\
\hline $\begin{array}{l}\text { Revised } \\
\text { Policy } 3 \\
\end{array}$ & $\begin{array}{c}2.74 \\
(0.68)\end{array}$ & $\begin{array}{c}3.02 \\
(0.69)\end{array}$ & $\begin{array}{c}2.86 \\
(0.94)\end{array}$ & $\begin{array}{c}2.53 \\
(0.98)\end{array}$ & $\begin{array}{l}3.09 \\
(0.74)\end{array}$ & $\begin{array}{c}3.14 \\
(0.72)\end{array}$ & $\mathrm{p}<.05$ & $\mathrm{p}<.001$ & $\mathrm{p}<.001$ \\
\hline $\begin{array}{l}\text { Revised } \\
\text { Policy } 4\end{array}$ & $\begin{array}{c}2.74 \\
(0.68)\end{array}$ & $\begin{array}{c}3.02 \\
(0.69)\end{array}$ & $\begin{array}{c}2.86 \\
(0.94)\end{array}$ & $\begin{array}{l}2.53 \\
(0.98)\end{array}$ & $\begin{array}{l}3.09 \\
(0.74)\end{array}$ & $\begin{array}{c}3.14 \\
(0.72)\end{array}$ & NS & $p<.001$ & $p<.005$ \\
\hline $\begin{array}{c}\text { Revised } \\
\text { Policy } \\
\text { Average }\end{array}$ & $\begin{array}{c}2.78 \\
(0.54)\end{array}$ & $\begin{array}{c}2.98 \\
(0.50)\end{array}$ & $\begin{array}{c}2.97 \\
(0.70)\end{array}$ & $\begin{array}{c}2.60 \\
(0.77)\end{array}$ & $\begin{array}{c}3.07 \\
(0.50)\end{array}$ & $\begin{array}{c}3.13 \\
(0.46)\end{array}$ & NS & $p<.001$ & $\mathrm{p}<.005$ \\
\hline
\end{tabular}

Note: Standard deviations in parentheses

Mean values for responses to 14 dependent measures. The p-values are from ANOVA's with profession and domain as the independent variables. The values for Policy All, Objection All and Revised Policy All are the average of each set of measures and the p-values are from separate ANOVA's comparing the listed professions.

The policy questions were on a scale from I (strongly disagree) to 5 (strongly agree).

The objection responses were on a scale from I (not at all reasonable) to 3 (very reasonable).

Revised policy questions were on a scale from I ("Disagree with the statement much more strongly") to 5 ("Agree with the statement much more strongly.').

question. Specifically, the physicians were much more negative toward the medical conflict of interest policy than the financial advice policy, whereas respondents from the NYT sample were much more even-handed. As can be seen, all 12 of these interactions are significant at the .005 level or greater.

\section{Reactions to Objections}

Physicians consistently endorsed objections to the COI policy more strongly in the medical as compared with the financial context (Figure 2). Similarly, financial planners more strongly endorsed objections to the financial COI policy than the medical 
Figure 2

Mean responses with $\mathbf{9 5 \%}$ confidence intervals (bars) to the six objections. Participants answered on a scale from "Not at all reasonable (I)" to "Somewhat reasonable (2)" to "Very Reasonable (3)."
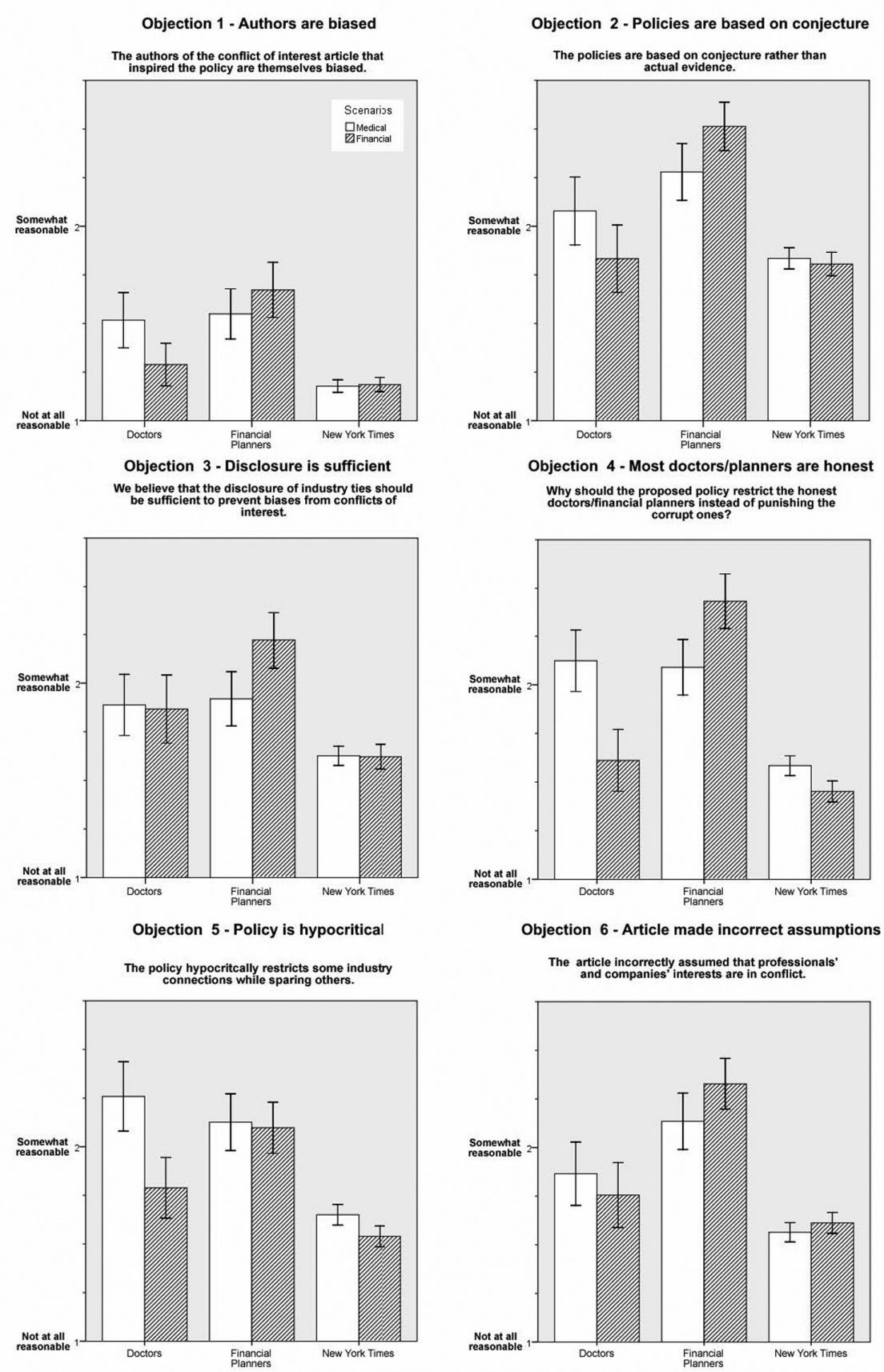

policy. Individual ANOVAs comparing the physicians with the NYT control group (Table 2) revealed a significant $(\mathrm{p}<.05)$ interaction between the domain to which the policy applied and the profession of the respondent for three of the six items (objections \#1, $\# 4$, and \#5) and a marginally significant interaction for objection \#2, indicating that physicians, as compared with control participants, viewed the objections

as more persuasive in the medical as compared to the financial context. Comparisons between the financial planners and the NYT control group showed similar results, with the financial planners consistently more strongly endorsing objections to the COI policy in the financial as opposed to the medical context (Figure 2 ). Individual ANOVAs revealed a significant ( $p<.05)$ interaction between the domain to which the policy 
applied and the profession of the respondent for three of the six items (objections \#2, \#4 and \#5). Comparisons between the physicians and financial planners revealed even stronger and more consistent asymmetries, with all six interaction effects significant at .05 or greater.
Response to the Policy After Reviewing Possible Objections

Figure 3 summarizes self-reported change in evaluation of the four summary statements about the COI policy after reviewing the objections. While reading the objections did not produce much change of opinion in any of the four scenario/profession combinations, there is a weak trend toward objections increas-

Figure 3

Impact of the objections on assessment of the COI policy. Mean responses with $95 \%$ confidence intervals (bars) to the four revised policy questions. Participants answered on a scale from "Disagree with the statement much more strongly (I)" to "No change in my position (3)" to "Agree with the statement much more strongly (5)".

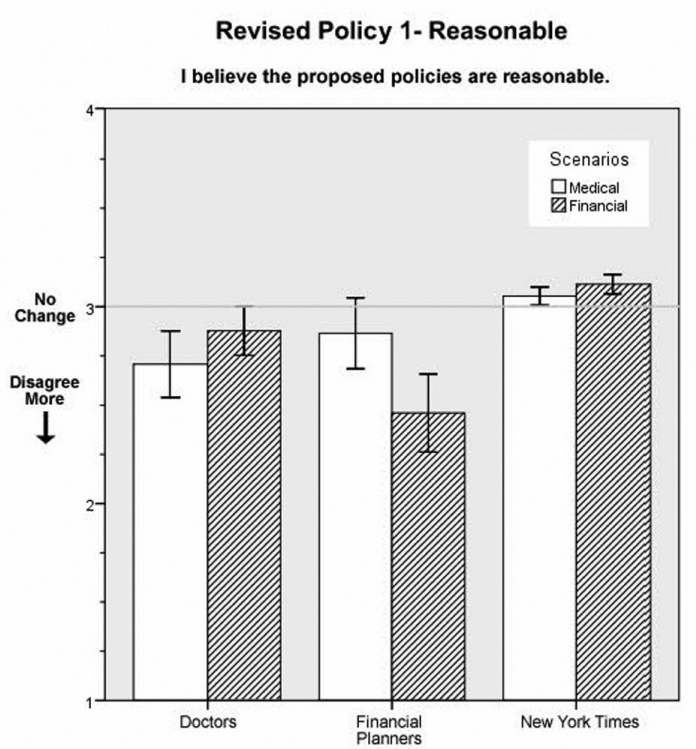

Revised Policy 3- Professionals don't need policy Doctors/Financial Planners are licensed professionals. We should be able to rely on them to avoid conflicts of interest

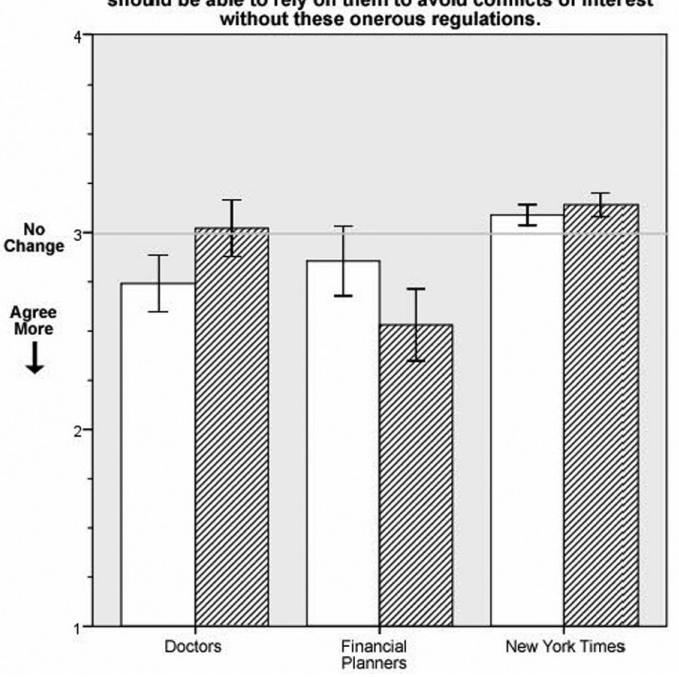

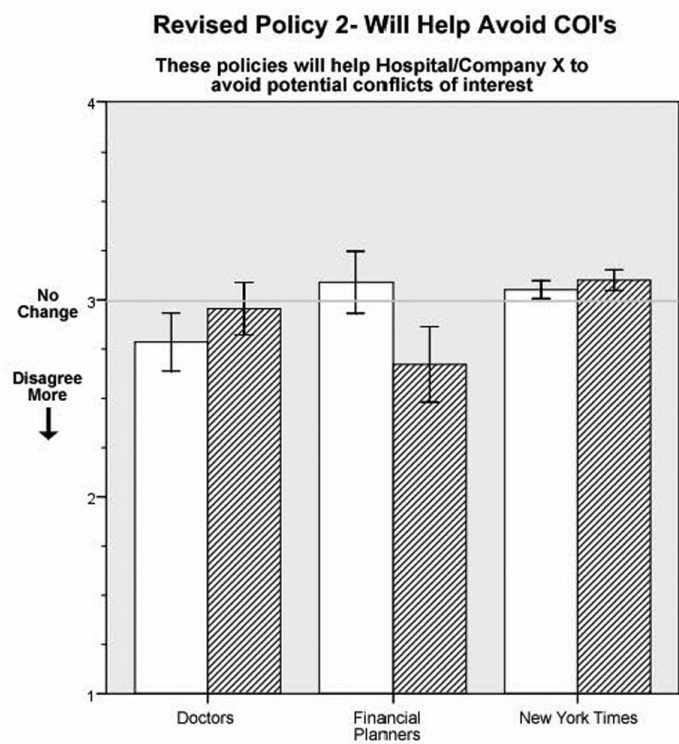

Revised Policy 4- Increases Trust Knowing that $X$ had implemented these guidelines would encourage me to seek medical/financial advice from them.

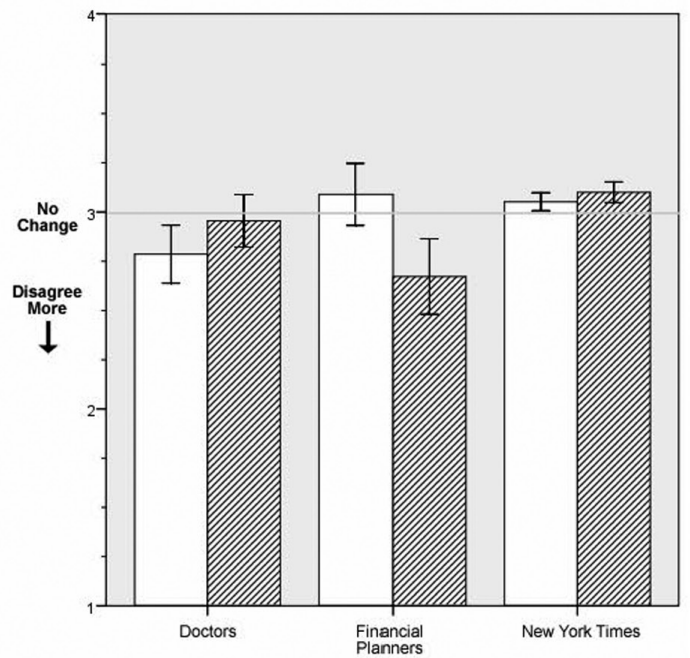


ing doctors' disagreement with the conflicts of interest policies more than non-doctors. The most striking, and only statistically significant, interaction effect is for the third policy question, "Doctors/Financial Planners are licensed professionals. We should be able to rely on them to avoid conflicts of interest without these onerous regulations" (Figure 3, \#3), an item on which doctors reported greater agreement by an average of about .2 but in which all of the three other combinations showed a decline in endorsement.

Financial planners, showed the same pattern as doctors, but even more strongly. Financial planners reported that consideration of the objections to the policy led them to be substantially more opposed to the COI policies applied to the financial domain. ANOVAs comparing the financial planners with the NYT control sample (Table 2) showed a significant interaction between profession and scenario: financial planners were more influenced by the objections in the financial scenario relative to the medical scenario than were the NYT group, with all four items significant at the .001 level.

Overall, the 14 items comprising the three sections reveal a strikingly consistent pattern. Physicians evaluating a conflict of interest policy in a medical context always provide the most extreme evaluations relative to the other groups in the medical scenario, in a direction consistent with motivated bias. Financial planners showed an even greater motivated bias when it came to the financial scenario. All 42 comparisons generated by pairwise comparisons of the three samples, looking across the 14 items, yielded means in the direction predicted by motivated bias.

\section{Additional Comparisons}

Some $(n=98)$ of the respondents in the NYT survey reported their occupation as physician. To determine whether these physicians display a similar pattern to those in the UPMC sample, we compared reactions to the two types of COI policies by physicians in the NYT sample to the remainder of the sample. The first cluster of results in Table 3 presents parallel analyses to Table 2, but restricted to omnibus MANOVA tests which aggregated over individual items from the three parts of the study. The only interaction effect that is significant is in revised reactions to the policies after reading the objections. Physicians in the NYT sample reported changing their evaluations of the policy more favorably, while non-physicians tended to evaluate the policy less favorably, following exposure to the objections. Although the other two interaction effects were not significant, probably due to reduced statistical power as a result of the smaller sample size, the results follow the same general pattern as the comparison of UPMC physicians to the NYT sample, suggesting that the results in Table 2 are not specific to UPMC physicians.

An analysis of the difference in responses between respondents in the NYT survey who self-reported working in the finance industry $(\mathrm{N}=67)$ to the rest of the sample also yielded a similar, albeit non-significant pattern of results to the comparison of the financial planners to the overall NYT sample. Given the small sample size, and the fact that few of those self-reporting working for the finance industry were probably specifically financial planners (who were the target of the scenarios), the lack of significance is not surprising.

To determine whether higher educational level might explain the differential assessment of the medical and nonmedical COI policy by physicians as compared to the NYT sample, the bottom section of Table 3 compares all physicians, from both the UPMC and NYT sample $(\mathrm{n}=277)$ to "other professionals" in the NYT sample who self-reported employment in industries where a college education might reasonably be expected: Finance/Investment, Medicine (but not doctors), Insurance, Real Estate, Education and Social Services and Public Administration ( $n=540$. The pattern of results is consistent with the analyses reported in Table 2, with a statistically significant effect for the interaction of profession and domain for the overall policy and the objections to the policy at $\mathrm{p}<.05$, suggesting that the observed effects do not result from the greater education level of physicians. Further analysis of the impact of respondent demographic characteristics on survey responses did not reveal interesting or significant differences in the means of responses within each set of samples (doctors, financial planners, and NYT respondents).

\section{Discussion}

Consistent with the predictions of research on motivated bias, physicians demonstrated a more critical, unfavorable attitude toward a conflicts of interest (COI) policy in a medical context compared with a nearly identical policy applied to financial investments. Physicians also viewed objections to the medical COI policy more favorably. This pattern was evident both for UPMC physicians and from physicians recruited from the NYT website. Physicians present a striking contrast to the control sample of respondents from the NYT website, which evaluated the two types of COI policies similarly. However, physicians are not alone in their bias; financial planners showed a similar bias against financial COI policies.

Research shows that motivated biases are widespread. Indeed, in our study, the financial planners 


\section{Additional Comparisons of Doctors vs. Others}

\begin{tabular}{|c|c|c|c|c|c|c|c|}
\hline Dependent variable & \multicolumn{5}{|c|}{$\begin{array}{c}\text { Profession } \\
\text { Domain (medical vs. financial scenario) }\end{array}$} & \multicolumn{2}{|c|}{ Significance } \\
\hline \multicolumn{8}{|c|}{ Sample: NY Times Doctors vs. NY Times Sample ( $\mathrm{N}=80$ vs. 1226) } \\
\hline Occupation Group: & physician & physician & $\begin{array}{l}\text { non- } \\
\text { physician }\end{array}$ & $\begin{array}{l}\text { non- } \\
\text { physician }\end{array}$ & $\begin{array}{l}\text { main effect: } \\
\text { profession }\end{array}$ & $\begin{array}{l}\text { main effect: } \\
\text { domain }\end{array}$ & interaction: \\
\hline Domain of COI: & $\begin{array}{l}\text { medical } \\
(n=52)\end{array}$ & $\begin{array}{l}\text { financial } \\
(n=28)\end{array}$ & $\begin{array}{l}\text { medical } \\
(n=694)\end{array}$ & $\begin{array}{l}\text { financial } \\
(n=532)\end{array}$ & & & $\begin{array}{l}\text { profession } \mathrm{x} \\
\text { domain }\end{array}$ \\
\hline Policy (All) & $3.52(1.05)$ & $3.94(0.84)$ & $3.76(0.83)$ & $3.80(0.74)$ & $p>.05$ & $p>.05$ & $p>.05$ \\
\hline Objection (All) & $1.69(0.54)$ & $1.55(0.39)$ & $1.57(0.43)$ & $1.55(0.42)$ & $p>.05$ & $p>.05$ & $p>.05$ \\
\hline Revised policy (All) & $2.98(0.67)$ & $3.22(0.50)$ & $3.07(0.47)$ & $3.12(0.45)$ & $p>.05$ & $p<.05$ & $p>.05$ \\
\hline \multicolumn{8}{|c|}{ Sample: All Doctors vs. Professionals ( $\mathrm{N}=259$ vs. 540 ) } \\
\hline $\begin{array}{l}\text { Occupation Group: } \\
\text { Domain of COI: }\end{array}$ & $\begin{array}{l}\text { physician } \\
\text { medical } \\
(\mathrm{n}=141)\end{array}$ & $\begin{array}{l}\text { physician } \\
\text { financial } \\
(n=118)\end{array}$ & $\begin{array}{l}\text { non- } \\
\text { physician } \\
\text { medical } \\
(n=298)\end{array}$ & $\begin{array}{l}\text { non- } \\
\text { physician } \\
\text { financial } \\
(n=242)\end{array}$ & $\begin{array}{l}\text { main effect: } \\
\text { profession }\end{array}$ & $\begin{array}{l}\text { main effect: } \\
\text { domain }\end{array}$ & $\begin{array}{l}\text { interaction: } \\
\text { profession } \mathrm{x} \\
\text { domain }\end{array}$ \\
\hline Policy (All) & $3.17(1.15)$ & $3.66(0.94)$ & $3.80(0.82)$ & $3.86(0.71)$ & $p<.001$ & $p<.001$ & $p<.001$ \\
\hline Objection (All) & $1.85(0.57)$ & $1.65(0.53)$ & $1.56(0.44)$ & $1.53(0.41)$ & $p<.001$ & $p<.001$ & $p<.05$ \\
\hline Revised policy (All) & $2.86(0.60)$ & $3.05(0.51)$ & $3.11(0.50)$ & $3.19(0.48)$ & $p<.001$ & $\mathrm{p}<.01$ & $p>.05$ \\
\hline
\end{tabular}

Note: Standard deviations in parentheses

Mean values for each set of responses to Policy, Objections and Revised Policy. The values are the average of each set of measures and the $p$ values are from the MANOVA test Roy's Largest Root.

exhibited motivated bias that was, if anything, even stronger than that displayed by the physicians. The prevalence of the phenomenon does not, however, diminish the significance of these results for physicians, who as a professional group are currently involved in numerous initiatives to reign in conflicts of interest that pervade medical research and practice.

It is difficult to be assured that educational level and the process that accompanies professionalization did not influence our results. We did not observe significant differences when we limited the sample from our control group to professionals, but we did not have a specific measure of educational status. However, differences in education between the two samples are unlikely to account for the observed effects. Users of the NYT website tend to be highly educated. In a previous study which used a similar link from the NYT website, $89 \%$ of respondents had a college degree or greater education. ${ }^{9}$

Since our respondents were obtained from voluntary requests to click on web links, the response rate for all three samples is relatively low. In the case of the NYT sample, moreover, we do not know what the non-response rate is - that is, we do not know how many people saw the link but chose not to click. Note, however, that our interest is not in either group's average response to the questions, but in their differential response to the questions cast in a medical or financial planning context. For sample bias to undermine our result, one would have to argue that the UPMC doctors are not representative of physicians in their differential response to the medical and financial COI policies compared to the response of the control group. The fact that doctors in the NYT sample displayed the 
same pattern as UPMC doctors argues against this interpretation.

Conflicts of interest are increasingly recognized as introducing various forms of bias into the practice of medicine, and increasing numbers of medical institutions are taking steps to control and manage these conflicts. ${ }^{10}$ However, the formulation and implementation of COI policies is complicated by the fact that those designing and implementing the policies are typically affected by them. Even if the designers of COI policies do not themselves have direct conflicts of interest, institutional conflicts of interest that often mirror, and in some cases contribute to, individual conflicts can bias the design and implementation of policies. ${ }^{11}$ Moreover, the effects of these institutional conflicts of interest can be exacerbated by the fact that they are difficult to identify and generally do not have to be reported by any single individual. ${ }^{12}$ Our research suggests that physicians may be subject to motivational bias when it comes to objectively assessing policies intended to control their own behavior. While physicians will inevitably and rightfully be involved in drafting and implementing a medical COI policy, the research reported here suggests that bringing outsiders into the COI policymaking process is advisable.

\section{Appendix A}

\section{Medical Scenario}

In this study we will ask you for your opinion regarding regulations to prevent conflicts of interest in medicine. We will also ask you to evaluate the quality of arguments that have been made against such regulations.

In order to provide the best possible care, doctors are required to continually educate themselves about the latest research, techniques and treatments available. Medical doctors are licensed professionals, and go through extensive training and testing to become certified by their professional society.

Pharmaceutical companies have an interest in increasing doctors' awareness of their products by aggressively marketing their products in order to stand out in a very crowded marketplace. There are thousands of prescription drugs approved for use today; by convincing doctors to recommend a specific drug over competitors, pharmaceutical companies can increase their revenue.

A recent article in the Journal of the American Medical Association highlighted the numerous potential conflicts of interest that doctors face and suggested some proposed measures that medical centers should put into effect.
Based on the guidelines provided in this article, a medical center in Pennsylvania (name withheld for reasons of privacy), has proposed to the doctors who work there a revised policy on conflicts of interest. In what follows, we will refer to the medical center as Hospital X.

The most significant of the policies proposed by Hospital X involve new limits on interactions between the employees of Hospital X (specifically doctors) and pharmaceutical representatives:

- Doctors will no longer be able to accept gifts of any type from pharmaceutical companies. This includes pens, coffee mugs, etc.

- Doctors will no longer be able to attend meals that are catered or paid for by representatives of pharmaceutical companies.

- Attendance at educational programs sponsored by pharmaceutical companies must be preapproved by management to ensure that these programs are truly educational and not marketing opportunities for the sponsors.

- To avoid even the appearance of conflicts of interest, pharmaceutical company representatives engaging in sales or marketing work will not be given access to hospital facilities.

Please respond to the following four statements by checking off whether you strongly disagree, disagree, neither agree nor disagree, agree, or strongly agree.

I believe the proposed policies are reasonable.

These policies will help Hospital X to avoid potential conflicts of interest.

Doctors are licensed professionals. We should be able to rely on them to avoid conflicts of interest without these onerous regulations.

Knowing that Hospital X had implemented these guidelines would encourage me to seek medical advice from them.

Several employees of Hospital X (mainly doctors) have strongly criticized the proposed regulations. What follows are a list of objections raised reproduced from letters written after the policy was proposed. After reading each objection, please provide your opinion about the quality of the argument.

\section{OBJECTION 1:}

Please read the following excerpt from a letter criticizing the proposed policy: 
"The authors of the conflict of interest article that inspired the policy are themselves biased. Research into their background has revealed that one of them, earlier in his career, obtained research support from an industrialist who has been accused of anticompetitive ('cut-throat') business tactics."

In your opinion, is this a reasonable argument against the new conflict of interest policy proposed by the management of Hospital X?

\section{OBJECTION 2 :}

Please read the following excerpt from a letter criticizing the proposed policy:

"The revised policies are based on conjecture rather than actual evidence. While it would be naïve to maintain that relationships with pharmaceutical companies do not introduce potential conflicts of interest, there is no evidence that free pens or coffee mugs affect medical decisions."

In your opinion, is this a reasonable argument against the new conflict of interest policy proposed by the management of Hospital X?

\section{OBJECTION 3 :}

Please read the following excerpt from a letter criticizing the proposed policy:

"We believe that the disclosure of industry ties should be sufficient to prevent biases from conflicts of interest. However, this approach is rejected out of hand by the $J A M A$ article authors and the framers of the proposed conflict of interest policy."

In your opinion, is this a reasonable argument against the new conflict of interest policy proposed by the management of Hospital X?

\section{OBJECTION 4:}

Please read the following excerpt from a letter criticizing the proposed policy:

"The media is apparently driving the reforms in our industry. High profile examples (apparent) conflicts of interest have given the media and by extension, the public, the impression that the relationship between doctors and the medical industry is rife with corruption. However, the vast majority of medical professionals continue to give honest advice without bias. Since corrupt medical professionals are already engaging in illegal activity, these restrictions will be ineffectual in deterring their actions. Why should the proposed policy restrict the honest doctors instead of punishing the corrupt ones?"

In your opinion, is this a reasonable argument against the new conflict of interest policy proposed by the management of Hospital X?

\section{OBJECTION 5:}

Please read the following excerpt from a letter criticizing the proposed policy:

"The present policy hypocritically restricts some industry connections while sparing other connections. For example, advertisements in medical journals and magazines and marketing booths at conventions are exempted but industry sponsored speeches and educational lunches are banned. If the speeches and lunches introduce conflicts of interest, then surely advertisements and marketing literature do as well.”

In your opinion, is this a reasonable argument against the new conflict of interest policy proposed by the management of Hospital X?

\section{OBJECTION 6:}

Please read the following excerpt from a letter criticizing the proposed policy:

"The JAMA article incorrectly assumed that doctors and pharmaceutical companies' interests are in conflict. We believe that while pharmaceutical companies are motivated by sales, given the transparent measures of drug efficacy, such as results in clinical trials, a doctor will be able to make a treatment decision without bias. Advertising is a necessary avenue for pharmaceutical companies to inform doctors and patients about new products in an extremely crowded and competitive market, thus restrictions will harm rather than protect patients."

In your opinion, is this a reasonable argument against the new conflict of interest policy proposed by the management of Hospital X?

Finally, we would like to know how your opinion about the proposed policy changes has been affected by reading the objections from some doctors. To remind you of the proposed policy, here is a list of the major changes: 
Doctors will no longer be able to accept gifts of any type from pharmaceutical companies. This includes pens, coffee mugs, etc.

Doctors will no longer be able to attend meals that are catered or paid for by representatives of pharmaceutical companies.

Attendance at educational programs sponsored by pharmaceutical companies must be preapproved by management to ensure that these programs are truly educational and not marketing opportunities for the sponsors.

To avoid even the appearance of conflicts of interest, pharmaceutical company representatives engaging in sales or marketing work should not be given access to hospital facilities.

For each of the questions we asked you before, please report how reading the objections has affected your opinion RELATIVE TO THE RESPONSES YOU GAVE WHEN YOU FIRST PROVIDED YOUR OPINION ABOUT THE POLICY AT THE BEGINNING OF THE SURVEY.

Disagree with the statement much more strongly

Disagree with the statement somewhat more strongly

No change in my position

Agree with the statement somewhat more strongly

Agree with the statement much more strongly

I believe the proposed policies are reasonable.

These policies will help Hospital X to avoid potential conflicts of interest.

Doctors are licensed professionals. We should be able to rely on them to avoid conflicts of interest without these onerous regulations.

Knowing that Hospital X had implemented these guidelines would encourage me to seek medical care from them.

\section{Financial Scenario}

In this study we will ask you for your opinion regarding regulations to prevent conflicts of interest in the financial planning industry. We will also ask you to evaluate the quality of arguments that have been made against such regulations.
Financial planners provide investment advice to their clients. They advise them on overall financial strategies as well as recommending particular stocks, mutual funds and other investment instruments. Financial planners are licensed professionals, and go through extensive training and testing to become certified by their professional society.

Investment companies (such as mutual fund companies) have an interest in aggressively marketing their products to financial planners in order to stand out in a very crowded marketplace. There are over eight thousand mutual funds on the market today; by convincing financial planners to recommend their products, investment companies can increase their revenue.

A recent article in the American Journal of Financial Planning highlighted the numerous potential conflicts of interest that financial planners face and suggested some proposed measures that the financial industry should put into effect.

Based on the guidelines provided in this article, a financial planning company located in Philadelphia, PA (name withheld for reasons of privacy), has proposed to the financial planners who work there a revised policy on conflicts of interest. In what follows, we will refer to the financial planning company as $\mathrm{X}$ Associates.

The most significant of the policies proposed by the management of $\mathrm{X}$ Associates involve new limits on interactions between the employees of X Associates (specifically financial planners) and representatives of investment companies:

- Financial planners will no longer be able to accept gifts of any type from investmentcompanies. This includes pens, coffee mugs, etc.

- Financial planners will no longer be able to attend meals that are catered or paid for by representatives of investment companies.

- Attendance at educational programs sponsored by investment companies must be pre-approved by management to ensure that these programs are truly educational and not marketing opportunities for the sponsors.

- To avoid even the appearance of conflicts of interest, investment company representatives will not be given access to financial planners' offices or to common areas where financial planners' clients might be present.

Please respond to the following four statements by checking off whether you strongly disagree, disagree, neither agree nor disagree, agree, or strongly agree. 
I believe the proposed policies are reasonable.

These policies will help X Associates to avoid potential conflicts of interest

Financial planners are licensed professionals. We should be able to rely on them to avoid conflicts of interest without these onerous regulations.

Knowing that X Associates had implemented these guidelines would encourage me to seek investment advice from them.

Several employees of X Associates (mainly financial planners) have strongly criticized the proposed regulations. What follows are a list of objections they raised, reproduced from letters written after the policy was proposed. After reading each objection, please provide your opinion about the quality of the argument.

\section{OBJECTION 1:}

Please read the following excerpt from a letter criticizing the proposed policy:

"The authors of the conflict of interest article that inspired the policy are themselves biased. Research into their background has revealed that one of them, earlier in his career, obtained research support from an industrialist who has been accused of anticompetitive ('cut-throat') business tactics."

In your opinion, is this a reasonable argument against the new conflict of interest policy proposed by the management of X Associates?

\section{OBJECTION 2:}

Please read the following excerpt from a letter criticizing the proposed policy:

"The revised policies are based on conjecture rather than actual evidence. While it would be naïve to maintain that relationships with financial product companies do not introduce potential conflicts of interest, there is no evidence that free pens or coffee mugs affect financial planning decisions."

In your opinion, is this a reasonable argument against the new conflict of interest policy proposed by the management of X Associates?
OBJECTION 3:

Please read the following excerpt from a letter criticizing the proposed policy:

"The present policy hypocritically restricts some industry connections while sparing other connections. For example, advertisements in financial journals and magazines and marketing booths at conventions are exempted but industry sponsored speeches and educational lunches are banned. If the speeches and lunches introduce conflicts of interest, then surely advertisements and marketing literature do as well."

In your opinion, is this a reasonable argument against the new conflict of interest policy proposed by the management of X Associates?

\section{OBJECTION 4:}

Please read the following excerpt from a letter criticizing the proposed policy:

"The media is apparently driving the reforms in our industry. High profile examples of conflicts of interest biasing the advice given to clients, such as the Merrill-Lynch scandal, have given the media and by extension, the public, the impression that the financial industry is rife with corruption. However, the vast majority of financial planners continue to give honest advice without bias. Since corrupt financial planners are already engaging in illegal activity, these restrictions will be ineffectual in deterring their actions. Why should the proposed policy restrict the honest financial planners instead of punishing the corrupt ones?"

In your opinion, is this a reasonable argument against the new conflict of interest policy proposed by the management of X Associates?

\section{OBJECTION 5:}

Please read the following excerpt from a letter criticizing the proposed policy:

"We believe that the disclosure of industry ties should be sufficient to prevent biases from conflicts of interest. However, this approach is rejected out of hand by the American Journal of Financial Planning article authors and the framers of the proposed conflict of interest policy." 
Zachariah Sharek, Robert E. Schoen, and George Loewenstein

In your opinion, is this a reasonable argument against the new conflict of interest policy proposed by the management of X Associates?

\section{OBJECTION 6:}

Please read the following excerpt from a letter criticizing the proposed policy:

"The article in the American Journal of Financial Planning incorrectly assumed that financial planners and financial product companies' interests are in conflict. We believe that while financial product companies are motivated by sales, given the transparent measures of performance, such as returns over the last 5 years, a financial planner and client will be able to make an investing decision without being biased. Advertising is a necessary avenue for financial product companies to inform investors and their planners about new products in an extremely crowded and competitive market, thus restrictions will harm rather than protect financial clients."

In your opinion, is this a reasonable argument against the new conflict of interest policy proposed by the management of X Associates?

Finally, we would like to know how your opinion about the proposed policy changes has been affected by reading the objections from some financial planners. To remind you of the proposed policy, here is a list of the major changes:

- Financial planners will no longer be able to accept gifts of any type from investment companies. This includes pens, coffee mugs, etc.

- Financial planners will no longer be able to attend meals that are catered or paid for by representatives of investment companies.

- Attendance at educational programs sponsored by investment companies must be pre-approved by management to ensure that these programs are truly educational and not marketing opportunities for the sponsors.

- To avoid even the appearance of conflicts of interest, investment company representatives should not be given access to financial planners' offices or to common areas where financial planners' clients might be present.

For each of the questions we asked you before, please report how reading the objections has affected your opinion RELATIVE TO THE RESPONSES YOU GAVE WHEN YOU FIRST PROVIDED YOUR
OPINION ABOUT THE POLICY AT THE BEGINNING OF THE SURVEY.

I believe the proposed policies are reasonable.

These policies will help X Associates to avoid potential conflicts of interest.

Financial planners are licensed professionals. We should be able to rely on them to avoid conflicts of interest without these onerous regulations.

Knowing that X Associates had implemented these guidelines would encourage me to seek investment advice from them.

\section{References}

1. T. A. Brennan et al., "Health Industry Practices That Create Conflicts of Interest: A Policy Proposal for Academic Medical Centers,» JAMA 295, no. 4 (2006): 429-433.; J. P. Kassirer, On the Take: How America's Complicity with Big Business Can Endanger Your Health (New York: Oxford University Press,2005).; T. P. Stossel, "Regulating Academic-Industrial Research Relationships - Solving Problems or Stifling Progress?” New England Journal of Medicine 353, no. 10 (2005): 1060-1055; D. G. Duvall, "Conflict of Interest or Ideological Divide: The Need for Ongoing Collaboration between Physicians and Industry," Current Medical Research and Opinion 22, no. 9 (2006): 1807-1812.

2. C. G. Lord, L. Ross, and M. R. Lepper, "Biased Assimilation and Attitude Polarization: The Effects of Prior Theories on Subsequently Considered Evidence," Journal of Personality and Social Psychology 37, no. 11 (1979): 2098-2109; Z. Kunda, "The Case for Motivated Reasoning," Psychological Bulletin 108, no. 3 (1990): 480-498.

3. P. Ditto and D. Lopez, "Motivated Skepticism: Use of Differential Decision Criteria for Preferred and Nonpreferred Conclusions," Journal of Personality and Social Psychology 63, no. 4 (1992): 568-584.

4. T. Gilovich, How We Know What Isn't So: The Fallibility of Human Reasoning in Everyday Life (New York: Free Press, 1991).

5. D. Simon, D. C. Krawczyk, and K. J. Holyoak, "Construction of Preferences by Constraint Satisfaction," Psychological Science 15, no. 5 (2004): 331-336.

6. E. Pronin, D. Y. Lin, and L. Ross, "The Bias Blind Spot: Perceptions of Bias in Self Versus Others," Personality and Social Psychology Bulletin 28, no. 3(2002): 369-381.; E. Pronin, T. Gilovich, and L. Ross, "Objectivity in the Eye of the Beholder: Divergent Perceptions of Bias in Self Versus Others," Psychological Review 111, no. 3 (2004): 781-799.

7. D. M. Cain and A. S. Detsky, "Everyone's a Little Bit Biased (Even Physicians)," JAMA 299, no. 24 (2008): 2893-2895.; J. Dana and G. Loewenstein, "A Social Science Perspective on Gifts to Physicians from Industry," JAMA 290, no. 2 (2003): 252-255; N. K. Choudhry, H. T. Stelfox, and A. S. Detsky, "Relationships between Authors of Clinical Practice Guidelines and the Pharmaceutical Industry," JAMA 287, no. 5 (2002): 612-617.

8. E. G. Campbell, K. S. Louis, and D. Blumenthal, "Looking a Gift Horse in the Mouth: Corporate Gifts Supporting Life Sciences Research," JAMA 279, no. 13 (1998): 995-999.; A. Wazana, "Physicians and the Pharmaceutical Industry: Is a Gift Ever Just a Gift?” JAMA 283, no. 3 (2000): 373-380; M. M. Chren and C. S. Landefeld, "Physicians' Behavior and Their Interactions with Drug Companies: A Controlled Study of Physicians Who Requested Additions to a Hospital Drug Formulary," JAMA 271, no. 9 (1994): 684-689;E. G. Campbell 
et al., "A National Survey of Physician-Industry Relationships," New England Journal of Medicine 356, no. 17 (2007): 17421750; E. A. Boyd and L. Bero, "Assessing Faculty Financial Relationships with Industry: A Case Study, JAMA 284, no. 17 (2000): 2209-2214.; K. S. Bigel, "The Ethical Orientation of Financial Planners Who Are Engaged in Investment Activities: A Comparison of United States Practitioners Based on Professionalization and Compensation Sources," Journal of Business Ethics 28, no. 4 (2000): 323-337; J. R. Boatright, "Conflicts of Interest in Financial Services," Business and Society Review 105, no. 2 (2000): 201-219.

9. S. I. Rick and C. E. Cryder, and G. Loewenstein, "Tightwads and Spendthrifts," Journal of Consumer Research 34, no. 6 (2008): 767-782.
10. E. A. Boyd, S. Lipton, and L. A. Bero, "Implementation of Financial Disclosure Policies to Manage Conflicts of Interest," Health Affairs 23, no. 23 (2004): 206-2014.

11. M. Barnes and P. S. Florencio, "Financial Conflicts of Interest in Human Subjects Research: The Problem of Institutional Conflicts," Journal of Law, Medicine छ Ethics 30, no. 3 (2002): 390-402.

12. Institute of Medicine, Conflict of Interest in Medical Research, Education, and Practice (Washington, D.C.: National Academies Press, 2009), available at <http://www.iom.edu/ CMS/3740/47464/65721.aspx> (last visited April 2, 2012). 